\title{
Facial nerve palsy and anti-Ku autoantibodies
}

\author{
Raoul Sutter • Bernard Mengiardi • \\ Daniela Benz • Ingmar Heijnen • Ludwig Kappos • \\ David T. Winkler
}

Received: 7 May 2011/Revised: 28 June 2011/Accepted: 2 July 2011/Published online: 18 July 2011

(C) Springer-Verlag 2011

Dear Sirs,

The $\mathrm{Ku}(\mathrm{Ku} 70 / \mathrm{Ku} 80)$ antigen is a DNA-binding nuclear protein involved in the repair of double-stranded DNA breaks by the non-homologous end-joining pathway [1]. Autoantibodies against $\mathrm{Ku}$ are infrequently detected and found in high titers in patients with connective tissue diseases and overlap syndromes [2-4].

In contrast to the low occurrence of anti-Ku antibodies, peripheral facial nerve palsy (PFNP) is a frequent disorder of multiple origins that often involves inflammatory mechanisms [5]. Recently, PFNP has been observed in three patients with anti-Ku antibodies and systemic autoimmune disorders [6].

A 40-year-old man suffering from psoriatic arthritis and a transient PFNP 5 years ago was admitted with weakness of his right facial muscles and taste disturbances on the

\author{
R. Sutter $(\square)$ \\ Department of Neurology and Intensive Care Unit, University \\ Hospital Basel, Petersgraben 4, 4031 Basel, Switzerland \\ e-mail: SutterR@uhbs.ch \\ B. Mengiardi \\ IMAMED, Radiologie Nordwest, Basel, Switzerland \\ D. Benz \\ Department of Rheumatology, University Hospital Basel, \\ Basel, Switzerland \\ I. Heijnen \\ Division of Medical Immunology, Laboratory Medicine, \\ University Hospital Basel, Basel, Switzerland \\ L. Kappos - D. T. Winkler \\ Department of Neurology, University Hospital Basel, \\ Basel, Switzerland
}

right half of the tongue. Examination revealed weakness of all facial muscles on the right with incomplete closure of his right eye. He was unable to frown on his right side. Rheumatological investigation revealed no signs of vasculitis or connective tissue disease. The psoriatic arthritis was in remission. MRI revealed gadolinium enhancement and thickening of the right facial nerve (Fig. 1a). Laboratory analysis excluded the presence of diabetes mellitus, infections, vitamin deficiencies, or monoclonal gammopathy, but revealed a high titer of antinuclear antibodies of 1:5,120. Indirect immunofluorescence on human epidermoid type 2 (HEp-2) cells (Inova, San Diego, CA) showed patchy nucleoplasmic and nucleolar staining (Fig. 1b), which prompted us to study the occurrence of anti-Ku antibodies. The presence of anti-Ku antibodies was confirmed by line immunoassay (Imtec, Wiesbaden, Germany) (Fig. 1b, insert). A stored serum sample obtained from the patient 7 years earlier also contained anti-Ku antibodies. Screening for antineuronal antibodies by indirect immunofluorescence on primate cerebellum tissue (The Binding Site, Birmingham, UK) revealed a similar nuclear staining pattern as observed in HEp-2 cells, most probably due to anti-Ku antibodies. Immunoblotting for known neuronal epitopes, (including $\mathrm{Hu}, \mathrm{Ri}, \mathrm{Yo}, \mathrm{CV} 2, \mathrm{Ma} 1, \mathrm{Ma} 2$, and amphiphysin) was negative. While other antinuclear specificities (anti-SS-A, anti-SS-B, anti-Mi-2, anti-neutrophil cytoplasmic antibodies, anti-cardiolipin, anti- $\beta 2$-glycoprotein) and anti-ganglioside autoantibodies were negative.

After treatment with $100 \mathrm{mg}$ oral steroids per day over 1 week, the PFNP showed a regression over several weeks.

We describe a patient with recurrent PFNP and high serum levels of anti-Ku autoantibodies. A potential association of PFNP and anti-Ku antibodies has been postulated by Gryga et al. [6] in a first report on three patients. The origin of PFNP is mostly idiopathic or infectious. However, 


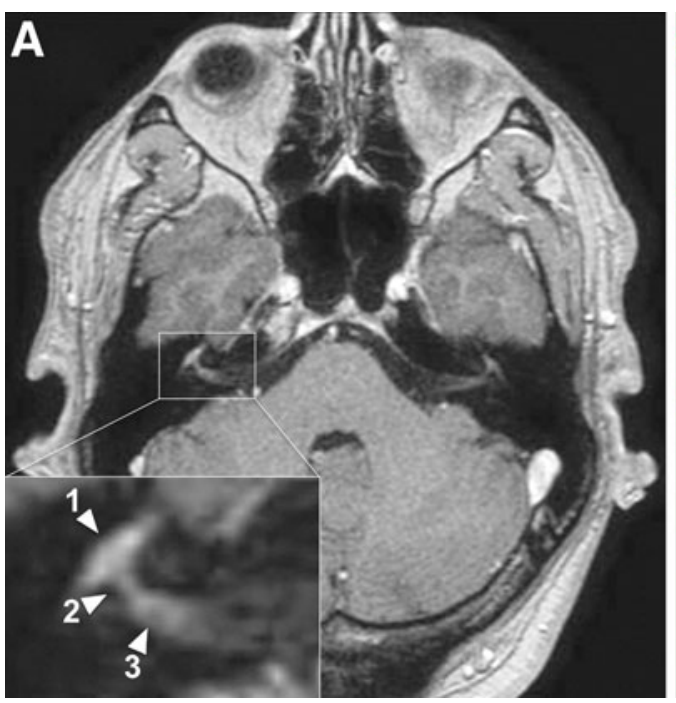

Fig. 1 MRI and immunofluorescence. a Contrast-enhanced axial T1weighted MR image (3D-Turbo-Field-Echo) of the intratemporal facial nerve: MR imaging shows strong enhancement of the right facial nerve in the distal intrameatal segment 1 , the labyrinthine segment 2 and an intensely enhancing and thickened geniculate ganglion region 3. b Anti-Ku antibodies immunofluorescence: anti-

a relevant part of cranial neuropathies is caused by inflammation. Inflammatory cranial neuropathies can be directly provoked by specific anti-neuronal antibodies as in Guillain-Barré syndrome or Miller-Fisher syndrome [5, 7, 8]. Alternatively, they may evolve from an indirectly antibody-associated pathogenesis, as in rheumatological disorders including systemic sclerosis, Sjögren syndrome, or mixed connective tissue disease [9]. In this light and given the recent publication of Gryga et al. [6], an association of anti-Ku antibodies and the recurrent PFNP of our patient seems probable. MRI revealed contrast enhancement in the distal intrameatal and the labyrinthine facial nerve segment, which is a typical feature in inflammatory peripheral facial nerve palsy [10-12].

We confirm a potential association of anti-Ku antibodies and PFNP and extend the observations of Gryga et al. [6] to patients without overt connective tissue disease. PFNP may be a leading symptom in patients with high titers of anti-Ku autoantibodies. It may occur in tandem with myositis, scleroderma, osteoarticular pain, sicca syndrome, and Raynaud's phenomenon [6] or, as in our case, with limited clinical rheumatological findings. While actually not suffering from a classical connective tissue disease, our patient did however had a history of psoriasis and thus signs of a systemic autoimmune disorder. As other antinuclear autoantibody specificities are absent in anti-Ku positive patients [2], positive antinuclear antibodies screening tests with a typical pattern on HEp-2 cells should be followed by specific anti-Ku antibody testing when PFNP is recurrent or associated with rheumatological

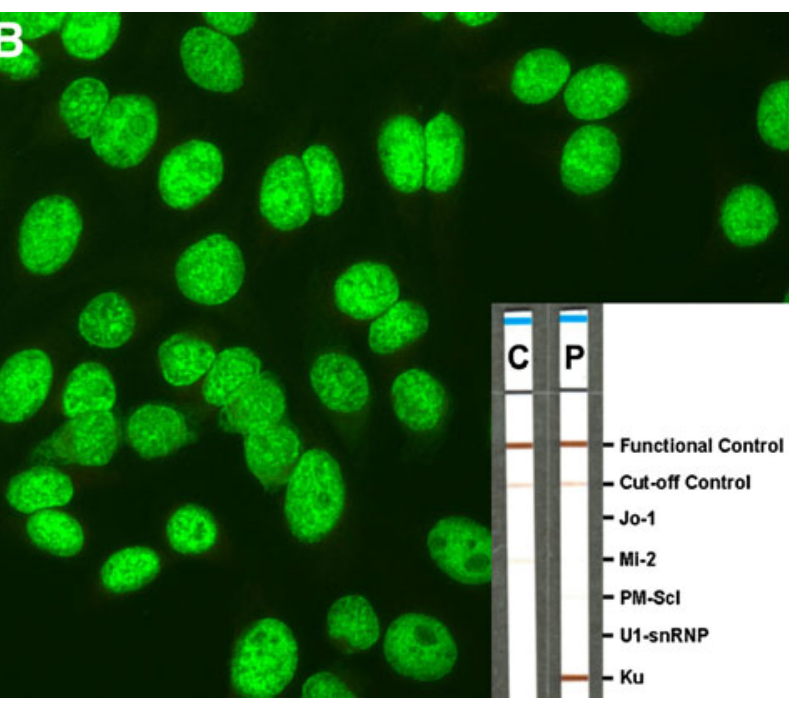

$\mathrm{Ku}$ antibodies revealed by indirect immunofluorescence on HEp-2 substrate cells, demonstrating patchy/homogeneous nucleoplasmic and nucleolar staining (large image). Specificity for $\mathrm{Ku}$ was confirmed by line-blot immunoassay (insert). Blots were incubated with serum from a healthy control individual $(\mathrm{C})$ and the patient $(\mathrm{P})$

findings. Further systematic testing of patients with PFNP for anti-Ku antibodies should be performed to search for more evidence of this possible association in patients with and without systemic autoimmune diseases.

Conflict of interest None.

\section{References}

1. Lieber MR, Ma Y, Pannicke U, Schwarz K (2004) The mechanism of vertebrate nonhomologous DNA end joining and its role in $\mathrm{V}(\mathrm{D}) \mathrm{J}$ recombination. DNA Repair (Amst.) 3:817-826

2. Rozman B, Cucnik S, Sodin-Semrl S, Czirják L, Varjú C, Distler O, Huscher D, Aringer M, Steiner G, Matucci-Cerinic M, Guiducci S, Stamenkovic B, Stankovic A, Kveder T (2008) Prevalence and clinical associations of anti-Ku antibodies in patients with systemic sclerosis: a European EUSTAR-initiated multi-centre case-control study. Ann Rheum Dis 67:1282-1286

3. Cavazzana I, Ceribelli A, Quinzanini M, Scarsi M, Airò P, Cattaneo R, Franceschini F (2008) Prevalence and clinical associations of anti-Ku antibodies in systemic autoimmune diseases. Lupus 17:727-732

4. Nihtyanova SI, Denton CP (2010) Autoantibodies as predictive tools in systemic sclerosis. Nat Rev Rheumatol 6:112-116

5. Van Doorn PA, Ruts L, Jacobs BC (2008) Clinical features, pathogenesis, and treatment of Guillain-Barré syndrome. Lancet Neurol 7:939-950

6. Gryga K, Milewski M, Zółciński M, Dyczek A, Musiał J (2009) Anti-Ku autoantibodies: series of 5 cases. Pol Arch Med Wewn 119:95-97

7. Gilchrist JM (2009) Seventh cranial neuropathy. Semin Neurol 29:5-13

8. Lo YL (2007) Clinical and immunological spectrum of the Miller-Fisher syndrome. Muscle Nerve 36:615-627 
9. Hagen NA, Stevens JC, Michet CJ (1990) Trigeminal sensory neuropathy associated with connective tissue diseases. Neurology 40:891-896

10. Hozumi A, Yuki N, Yamazaki K, Hirata K (1999) Facial diplegia with paraesthesias facial nerve enhancement in three-dimensional MRI. J Neurol Neurosurg Psychiatry 66:688

11. Coddington CT, Isaacs JD, Siddiqui AQ, Andrews TC (2010) Neurological picture. Bilateral facial nerve palsy associated with
Epstein-Barr virus infection. J Neurol Neurosurg Psychiatry 81:1155-1156

12. Sartoretti-Schefer S, Kollias S, Wichmann W, Valavanis A (1998) T2-weighted three-dimensional fast spin-echo MR in inflammatory peripheral facial nerve palsy. Am J Neuroradiol 19:491-495 